\title{
A study of rumen fill on eating behaviour and voluntary intake in sheep using rumen digesta exchange method
}

\author{
K. Izumi ${ }^{1}$, S. Nagata ${ }^{2}$, J. Nakamura ${ }^{2}$ and M. Okamoto ${ }^{2}$ \\ ${ }^{1}$ Research Farm, Rakunogakuenn University, \\ ${ }^{2}$ Faculty of Dairy Science, Rakunogakuen University \\ 069-8501, Ebetsu, Hokkaido, Japan
}

\begin{abstract}
In order to test the influence of rumen fill on eating behaviour and voluntary intake in sheep offered hay, the rumen digesta from sheep at two hours after feeding was exchanged with that from sheep immediately before feeding. Four rumen-cannulated sheep were fed with grass hay ad libitum. Two pairs were made consisting of one sheep in the group fed at 8.30 and another sheep in the 10.30 group. The rumen digesta of the two sheep within a pair were exchanged at 10.30. We analysed the relationship between eating behaviour and rumen fill, and discussed the mechanism of voluntary intake.
\end{abstract}

KEY WORDS: rumen fill, first meal, voluntary intake, eating behaviour, sheep

\section{INTRODUCTION}

The voluntary intake of ruminants consists of the total of meals consumed in a day. Especially the first meal with the distribution of feed plays a major roll in feed intake regulation (Baumont et al., 1989). It is thought that the termination of the first meal is mainly influenced by physical fill and chemical sensitivity in the rumen wall.

The objective of this study was to investigate the influence of rumen fill on eating behaviour and voluntary intake in sheep offered hay by using the rumen digesta exchanging method.

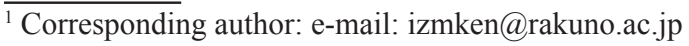




\section{MATERIAL AND METHODS}

Four rumen-cannulated sheep were fed with grass hay ad libitum. To exchange the rumen digesta from sheep at two hours after feeding with that from the sheep immediately before feeding, two sheep received feed at $8.30 \mathrm{~h}$ (the group fed at 8.30 ) and the other two sheep received at $10.30 \mathrm{~h}$ (the group fed at 10.30). Two pairs were made consisting of one sheep in the group fed at 8.30 and the other sheep in the 10.30 group. Two 18-day experiments, which consisted of 10 days adaptation period, the day of rumen digesta exchange (d 11), recovery period (3 days), the day of rumen digesta exchange (d 15) and recovery period (3 days), were carried out. The rumen digesta of the two sheep within a pair were exchanged at 10.30. The amount of rumen digesta and particle size distribution was measured in both groups. Voluntary intake was measured every day. Eating behaviour and rumination activity was investigated by analysing of jaw movement.

\section{RESULTS}

Intake of dry matter (DM) and neutral detergent fibre (NDF) on the day of digesta exchange was significantly greater for sheep fed at 8.30 than for those fed at 10.30 (Table $1 ; \mathrm{P}<0.05$ ). When daily intake on the exchange day was compared

Table 1. Voluntary intake, time spent eating and rumination and the duration of first meal in both groups

\begin{tabular}{|c|c|c|c|c|}
\hline & \multicolumn{2}{|c|}{ Feeding at $8.30^{1}$} & \multicolumn{2}{|c|}{ Feeding at $10.30^{2}$} \\
\hline & mean & Std & mean & Std \\
\hline \multicolumn{5}{|l|}{ Dry matter intake } \\
\hline adaptation period, $\mathrm{g} / \mathrm{d}$ & 1412.7 & 183.9 & 1366.9 & 241.6 \\
\hline the day of rumen digesta exchange ${ }^{3}, g / d$ & $1855.8^{\mathrm{a}}$ & 519.4 & $1396.4^{\mathrm{b}}$ & 484.2 \\
\hline \multicolumn{5}{|l|}{ Eating time } \\
\hline adaptation period, $\mathrm{min} / \mathrm{d}$ & $401.8^{\mathrm{A}}$ & 48.4 & $374.8^{\mathrm{B}}$ & 39.1 \\
\hline the day of rumen digesta exchange, $\mathrm{min} / \mathrm{d}$ & $434.1^{\mathrm{a}}$ & 82.3 & $352.6^{\mathrm{b}}$ & 108.1 \\
\hline first meal before exchanging rumen digesta, min & 81.4 & 65.3 & - & - \\
\hline $\begin{array}{l}\text { the meal immediately after exchanging rumen } \\
\text { digesta }^{3}, \text { min }\end{array}$ & $130.8^{\mathrm{a}}$ & 76.0 & $80.6^{\mathrm{b}}$ & 32.9 \\
\hline \multicolumn{5}{|l|}{ Rumination time } \\
\hline adaptation period, $\mathrm{min} / \mathrm{d}$ & 583.3 & 27.2 & 528.8 & 74.8 \\
\hline the day of rumen digesta exchange, $\mathrm{min} / \mathrm{d}$ & 514.6 & 26.9 & 564.2 & 69.8 \\
\hline
\end{tabular}

${ }^{1}$ this group had eaten for $2 \mathrm{~h}$ at exchange of rumen digesta

2 this group did not eat yet at exchange of rumen digesta

${ }^{3}$ the time of exchange was at 10.30

${ }^{\mathrm{a}, \mathrm{b}} \mathrm{P}<0.05,{ }^{\mathrm{A}, \mathrm{B}} \mathrm{P}<0.10$ 
to the adaptation period, there was a tendency of increase in the group fed at 8.30 , while the 10.30 group was not affected. The daily eating time on the day of rumen digesta exchange was significantly longer for the sheep fed at 8.30 than for those fed at $10.30(\mathrm{P}<0.05)$, but the daily rumination time was not affected by the digesta exchange. The duration of the first meal on the exchange day was similar between the two groups, and the meal length immediately after the second distribution for the 8.30 group was $130.8 \mathrm{~min}$.

$\mathrm{DM}$ and NDF weight of rumen digesta was greater in the sheep fed at 8.30 than in those fed 10.30 (Table 2; $\mathrm{P}<0.10$ ). Large particle content in rumen digesta fed at 8.30 was higher than the group fed at $10.30(\mathrm{P}<0.05)$. Small particle content was lower in the 8.30 sheep than in the 10.30 sheep $(\mathrm{P}<0.05)$.

\section{DISCUSSION}

Because there was a great difference in the dry matter weight of rumen digesta and the large particle content, it was realized that the degree of rumen physical fill in the 8.30 group was higher than that in the 10.30 group at digesta exchanging.

The rumen digesta in the 8.30 group increased from $1133.5 \mathrm{~g}$ DM (before a distribution of feed) to $1424.9 \mathrm{~g} \mathrm{DM}$ ( $2 \mathrm{~h}$ later), and then the digesta decreased to $1133.5 \mathrm{~g}$ DM following the digesta exchange. As a result of this, second large meal occurred with refeeding (130.8 $\mathrm{min})$. On the contrary, although the rumen digesta in the 10:30 group increased from $1133.5 \mathrm{~g}$ DM to $1424.9 \mathrm{~g}$ DM following the digesta exchange without feed intake, the large first meal occurred after a distribution of feed (80.6 min). Accordingly, the reduction of voluntary intake was not recorded in the 10.30 group. The results of this experiment suggest that there was a difference in the response of sheep to an increase or a decrease in rumen fill.

Table 2. Weight and particle size distribution of rumen digesta in both groups

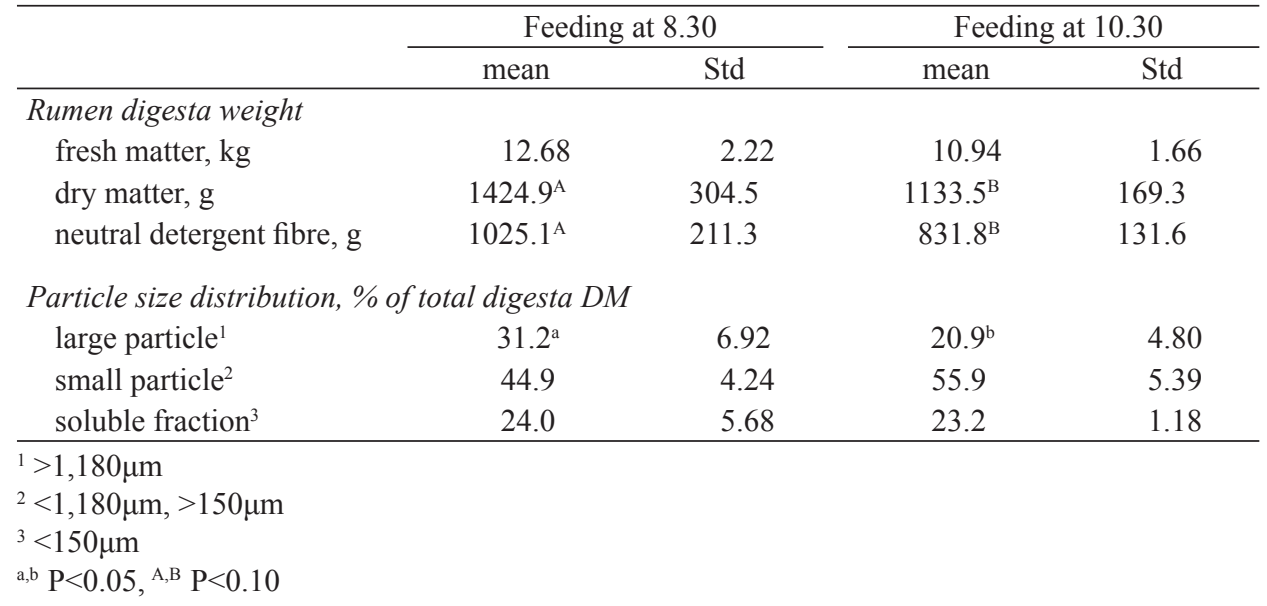




\section{RESEARCH OF RUMEN FILL BY RUMEN DIGESTA EXCHANGE METHOD}

\section{CONCLUSIONS}

It was concluded that decreasing of rumen fill made the second meal larger. On the other hand, from the result of the group fed at 10.30, it is suggested that there will be some factors to prompt eating in addition to rumen fill.

\section{REFERENCES}

Baumont R., Brun J.P., Dulphy J.P., 1989. Influence of the nature of hay on its ingestibility and the kinetics of intake during large meals in sheep and cows. XVI International Grassland Congress, Nice (France), pp. 787-789 